\title{
fi) $I=\mathbb{R} \mathbb{R}$ EalLIL
}

Journal of Research on English and Language Learning

http://riset.unisma.ac.id/index.php/JREALL/user DOI: $10.33474 / \mathrm{j}$-reall.v2i1.9519

Volume 2 | Number 1 | p. 61-67

Published on January $19^{\text {th }}, 2021$

\section{The effectiveness of using metacognitive strategy to teach online reading comprehension for English Young Learners}

\author{
Nur Jamilah \\ University of Islam Malang, Indonesia \\ missmeela3@gmail.com \\ *) correspondence: missmeela3@gmail.com
}

\begin{abstract}
This research aims to identify the effectiveness of using metacognitive strategy in teaching online descriptive text. Fifty students of the second year at MA Al-Istiqomah, Mojokerto were involved in this study. This research is One-Group Pretest-Posttest Design. Students' reading achievement based on the minimum passing score and field notes were the instruments to get the data. The present study results in the implementation of metacognitive strategy improved the students' skill in reading online descriptive text especially in ascertaining main idea, supporting idea and topic sentence. This showed the significant improvement of the students' reading comprehension skills of an online descriptive text when implementing metacognitive strategy on their learning process. The finding of the present study is expected to be applicable in the online based class during this pandemic Covid - 19 .
\end{abstract}

Keywords: online reading comprehension; descriptive texts; metacognitive strategy

\section{INTRODUCTION}

In fact, for some students, reading is not a favorite subject. For those who cannot enjoy reading, this activity may be a boring one. They are not able to easily understand and get the deeper comprehension of reading activity. Some teachers tend to only give the students a passage and ask them to read then translate the text. This is exactly causing the stagnant and flat activity in the classroom. More time is needed to encourage the students relishing reading as an attractive activity instead of being the repulsive one (Etfita, 2014).

Reading comprehension takes an important part in EFL learning process. The 2013 curriculum stated that several types of text must be taught intensively to the students in senior high school level. Some of them are four types of texts, they are narrative, procedural, recount and descriptive passage (Antoni, 2010). For that purpose, the readers need deeper thinking process about the words that may just have read or seen on the text for the first time (Setiyadi et al., 2019). Not only reading but the students must try to derive the meaning of each word then correlate the meaning into the whole perception of the comprehensible sentence also. In easier term, reading comprehension is the ability to read, comprehend, process, and recall what was just read (Ganie et al., 2019). This needs a higher reading and thinking activity level. While Cornoldi (2013) declares that comprehend in reading means the students should understand of all the aspect of the text fully.

In this pandemic Covid-19 era, most teaching learning process is taken in online-based class, as well as reading comprehension learning. Thus Coiro (2014) states that young learners are increasingly becoming disclosed to web-based reading activity and electronic books (e-books), the readers are becoming more interested in both sources which have been found to encourage their language and literacy skills such as word recognition, phonological awareness and fluency. The twenty-first century era brings the literacy today not only as the traditional print texts but also the proficiency in the digital ones (Ciampa, 2012).

Thus, the students need specific strategy in comprehending online based texts. Metacognitive strategy is one of the solutions in comprehending online reading passage. The metacognition terminology comes with the definition as the ability of someone to know how well the cognitive 
functions work together with monitoring ability while reading text and those must be controlled and adjusted based on the needs of the learning treatment, process and goal (Mitsea, 2019). Thinking process of thinking is also the definition of metacognition based on Pavel Doulik (Doulík et al., 2015). Planning, monitoring, and evaluation are the steps of metacognition regulation and this is regarded as "self-management" of cognition implying contemplative "self-appraisal" that corroborates awareness and has been considered as executive control (Mitsea, 2019).

Mitsea (2019) In learning process, the correlation between the levels of self-confidence and the metacognitive strategy is focusing on three fundamental skills (planning, monitoring and evaluation) with the pursuing metacognitive strategies:

1. Make a note

2. Summing up

3. Drag a draft

4. Contemplating

5. Retelling

6. Reexamining

The results of the study showed that strategies as making a note, summing up, dragging a draft and contemplating were mostly used, while retelling and reexamining means were averages indicating that the students prefer less retelling and reexamining. This study proved that the use of metacognitive strategies created higher level of students' confidence.

The previous study towards metacognitive strategy concerned on the implementation of metacognitive strategies in learning teaching process especially reading comprehension class. The study used Experimental Research Design which is conducted at SMP Unggul Pidie Jaya, 50 students were involved as the participant. The two classes that were randomly chosen were divided into two categories, they were Experimental Group (EG) and the rest is Control Group (CG). The result was computed statistically to know the significant difference between Experimental Group (EG) and Control Group (CG) mean score after applying metacognitive strategy. In addition, after applying metacognitive strategies, the students' motivation was increasing up to $72 \%$ and their knowledge was rising up to $64 \%$. After comparing the mean score of each category, the $t$-value showed that there was significant increasing score of the experimental group in comprehending reading text after implementing metacognitive strategy. This study proved that metacognitive strategy was the overall solution in teaching and learning process (Usman et al., 2017).

Hapsari (2019) focused on the training of metacognitive strategies in teaching reading comprehension. This study was conducted under Experimental Research Design, especially Randomized Matched Subjects Pre-Test Post Test Design. The study was conducted at Universitas Islam Darul 'Ulum Lamongan with the participants was from the $3^{\text {rd }}$ and the $5^{\text {th }}$ semester at 2018/2019 academic year. The instrument was reading comprehension on English Proficiency Test (EPT/TOEFL like). Based on paired sample t-test, the significance value was 0.008 , that was lower than 0.05 . This proved that the students who are trained by metacognitive strategies on their reading process achieved better score than those who were only applying conventional strategy when they were doing reading process.

While Jaleel \& Premachandran (2016) indicated that the secondary school students are identically distributed among each group in the Metacognitive Awareness. The researchers stated that "when teachers make aspects of learning and problem-solving visible, and help students identify their own strengths and strategies, they can have a lasting impact on how their students learn once they leave their classrooms.

In addition concerning to this topic, Misa (2014) focused on the implementation of metacognitive strategy on the students' reading comprehension on analytical exposition text at University of Timor using Collaborative Action Research (CAR). The second semester students were the subject of the research, they consisted of 29 students. To collect the data, the three steps of metacognitive strategy, planning-monitoring-evaluating, were employed. The students could more easily find the main topic, supporting idea and topic sentence using metacognitive strategy. It was 
obviously turned out that the students' average score was significantly increasing up to $68.51 \%$ after enforcing metacognitive strategy.

Based on the researcher's observation, and the previous study plus the above account, the goal of teaching and learning process specifically online descriptive text would be more comprehensively achieved by implementing the metacognitive strategy. Hence, the researcher carried on One-Group Pretest-Posttest Design by holding metacognitive strategies in teaching descriptive online reading comprehension to second grade students at a senior high school, MA Al-Istiqomah, Mojokerto. The important focus of the study was riveted on the effectiveness of using metacognitive strategy to teach online reading using descriptive text to second year students at a senior high school, MA Al-Istiqomah, Mojokerto by comparing the result of pretest and posttest results. This study goes with the alternative hypothesis that the second-grade students of MA Al-Istiqomah, Mojokerto will get better score by implementing the metacognitive strategy on their online descriptive text comprehension. Whereas the null hypothesis states that there is no significant better achievement of the second-grade students of MA Al-Istiqomah after implementing the metacognitive strategy on their reading process. Hence, the study goes with the research problem as follows; do the second-year students of MA Al- Istiqomah have better score in comprehending online descriptive text using metacognitive strategy?

\section{METHODS}

This present research focalized on detecting the effectiveness of employing metacognitive strategies in teaching online descriptive text. For this aim, the researcher expended One-Group Pretest-Posttest Design. Another name for this is Pre-Experimental Research Design (Latief, A.M. 2016). The significance of the strategy is measured by comparing the mean score of the pretest and the posttest phase. However, when the posttest mean score is higher than the pretest mean score, this can be reasoned out that the treatment or the strategy implementation is becoming effective.

TABLE 1: One Group- Pretest-Posttest Design

\begin{tabular}{ccc}
\hline Pretest & Treatment & Posttest \\
\hline $\mathrm{O}_{1}$ & $\mathrm{X}$ & $\mathrm{O}_{2}$ \\
\hline
\end{tabular}

This study was conducted at MA Al-Istiqomah, Mojokerto. The participant of the existing research was fifty second year students of MA Al-Istiqomah at the academic year 2020/2021 from the three classes of all. The researcher, as well as the English teacher of MA Al-Istiqomah, used tests as the instrument to get the data. The tests were compiled to identify more deeply about the students' capability in comprehending and identifying the main idea, topic sentence as well as the supporting sentence of the online descriptive passage before and after implementing the steps constructed as metacognitive strategy.

In this research, the researcher took 45-minute long for each meeting per day and lasted for four meetings in two weeks based on the students' timetable. The first meeting was used for the pretest phase. Then the second and the third ones were for training the metacognitive strategies with an interesting practical phase. And the last meeting, the fourth day, was used to conduct the posttest. The pretest and posttest are in form of an online descriptive text which is categorized as HOTS (High Order Thinking of Skill) reading taken from web resource.

There are three stage of questions that are now becoming more popular on 2013 curriculum (K-13). They are LOTS (Lower Order Thinking Skill), MOTS (Medium Order Thinking of Skill) and the last is HOTS (High Order Thinking of Skill). (Ahmad et al., 2018) explained that metacognitive, reflective, logical, critical, and creative thinking skills are the important processes at HOTS stage. They are triggered when the readers come across uncertainties, dilemmas, unacquainted problems, or questions. It can be seen that HOTS is the highest stage of all.

The pretest-posttest passage entitled "What's So Great about the Jasmine Flower?". 45 minutes were given then the students could click the link and comprehend the linked-online descriptive passage. After the passage, there were ten questions to answer relating to the comprehensions. The questions are in form of objective and subjective types. The first five objective questions are in form of multiplechoice test, consists of $A, B, C, D$, and $E$ options to select. Hence, the subjective questions are in 
form of essay, this type of question stimulate the students' ability to answer and state their idea more freely. They covered the main idea together with the supporting idea and the topic sentence. The intension of subjective question is seeking the response or answer by reflecting the reader's experience, prior knowledge, preferences, advices, and opinion. Whilst, the objective question is focusing on the reader's response or answer relating to some common experiences or factual knowledge (Liu \& Jansen, 2015)

The effectiveness of the metacognitive strategy is measured by comparing the average score of the pretest and the posttest. The minimum passing score for English is 75, based on the 2013 curriculum for senior high school from Mojokerto Ministry of Religion. In term of gaining the effectiveness of learning goals, the researcher added the "Three-time repeating" phase in evaluation session. This was the researcher's improvement idea. The students had to repeat the strategies at least three times, with different three passages, to have deeper comprehension and more applicable metacognitive strategies to obtain. The researcher (as the English teacher) intended to make the students get used to apply this strategy on their online reading process.

And so, the researcher calculated the data by utilizing paired t-test. In this step, the researcher used IBM SPSS Statistic Version 20. SPSS is the abbreviation of Statistical Package for the Social Sciences. This program can work to analyze data collected from observations, surveys, tests, etc. It can effectively show the data analysis variation and the presentation functions, including graphical presentation of data and statistical analysis

\section{RESULTS AND DISCUSSION}

The implementation of metacognitive strategy in an online descriptive text was done in an attempt to seek the significant improvement on teaching and learning process specifically on English reading class of the second-year students of MA Al-Istiqomah, Mojokerto. The results showed that the students who were trained with metacognitive strategies turned into more riveted on the reading stuff and more interested in comprehending the passage fully. The planning and monitoring stage were really helpful for the students to build their preliminary thought. Moreover, the students also hardly tried to foretell the answers correctly and made a clear outline with note-taking rule, placed the structure of the text, and so forth. However, (Usman et al., 2017) have indicated that students who intensively use and learn metacognitive strategy succeeded the reading process and obtained satisfying reading goal. Their nature sense of reading such as problem-solving skill is much better germinated and they much learned to coordinate better knowledge. This automatically affected their academic success.

The three fundamental skills of metacognition (planning, monitoring and evaluation) became the focus of this study, and the metacognitive strategies as follows:

1. Make a note; this beginning step is recording every points or main ideas when reading the passage. The readers may write information which they considered as the important one.

2. Summing up; the second step of metacognition process is writing some brief statements which are symbolizing the main and supporting ideas.

3. Drag a draft; this focuses on the main points of the important information in a hierarchical format.

4. Contemplating; the readers are asked to relate the existing information they had with their prior knowledge.

5. Retelling; the readers are loudly stating the points with asking and answering sessions.

6. Reexamining; the readers are doing self-questions and repeating learning process.

Table 2. The Metacognitive treatment

\begin{tabular}{clc}
\hline Pretest & Metacognitive Strategy & Posttest \\
\hline The mean score & Metacognitive Process & The mean score \\
71.96 & 1. Make a note & 84.12 \\
& 2. Summing up & \\
3. Drag a draft &
\end{tabular}




\author{
4. Contemplating \\ 5. Retelling \\ 6. Reexamining
}

Table 2 showed that there was an increasing on the mean of the students' score after applying the metacognitive strategies. At the pretest set, the students' mean score was below the minimum passing score. Whilst at the posttest, the students' average score was above the minimum passing score. For English, the minimum passing score is 75 .

TABLE 3. Paired Samples Statistics

\begin{tabular}{llllcc}
\hline & & Mean & N & Std. Deviation & Std. Error Mean \\
\hline \multirow{2}{*}{ Pair 1 } & Pretest & 71.96 & 50 & 8.903 & 1.259 \\
& Posttest & 84.12 & 50 & 8.035 & 1.136 \\
\hline
\end{tabular}

Table 3 discussed the output of Paired Samples T-test. Statistics distributed the mean score of pretest set was 71.96 and mean score of posttest set was 84.12, whilst the value of $\mathrm{N}$ for both pretest and posttest are 50. And so, the deviation of posttest means score and pretest mean score was 12.16. Meantime, the standard deviation of pretest score was 8.903 and standard deviation of posttest score was 8.035 . The standard error of pretest mean was 1.259, whilst the standard error of posttest mean was 1.136.

TABLE 4. Paired Samples Correlations

\begin{tabular}{lllcl}
\hline & & $\mathrm{N}$ & Correlation & Sig. \\
\hline Pair 1 & Pretest \& Posttest & 50 & .783 & .000 \\
\hline
\end{tabular}

Table 4 above showed the output of Paired Samples Correlations between the pretest and the posttest score. That table told the numeric of both samples' correlations were 0.783 and the numeric of significance value was 0.000 . It clearly intended the large numeric significance 0.000 was lower than 0.05. Based on this data, the hypothesis was understandably accepted that the metacognitive strategy was significantly influencing the students' learning process and was better affecting the students' achievement.

TABLE 5. Paired Samples Test

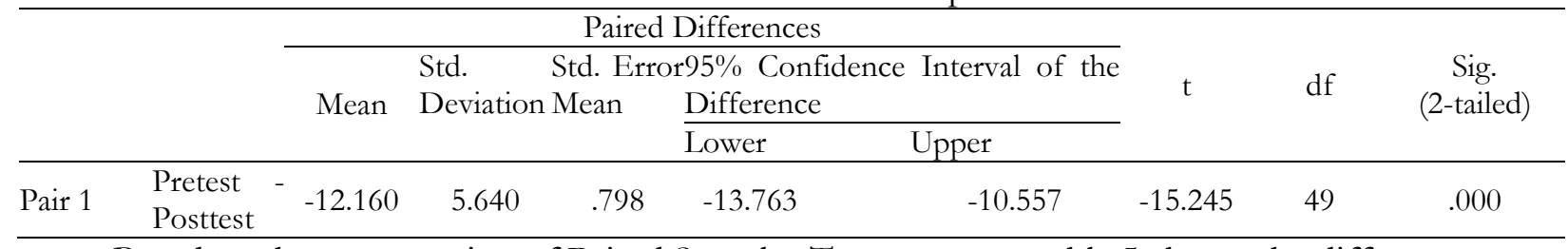

Based on the computation of Paired Samples Test as seen at table 5 above, the difference mean between pretest and posttest score was 12.160 or 84.12 minus 71.96 equals with 12.16 . The standard deviation of both samples was 5.640 while the standard error mean was 0.798 and the dispute of difference ranged over 13.763 to 10.557 (95\% Confidence Interval of the Difference). The Significance (2-tailed) of Paired Samples Test was 0.000, this was lower than 0.05. It implies the significance difference between the students' pretest and posttest score. In addition, based on this data, it can be concluded that the implementation of metacognitive strategy on the students' reading process is greatly influencing the students' score.

Metacognitive strategy is good at encouraging the students' motivation to be more independent reader and avoiding the anxiety. Metacognitive strategy also guides the students to kindly be able to modulate her or his learning process and thinking. The students who are aware of metacognitive strategy more enjoying their learning process and easily identifying what and how the most relevant approaches trick to fulfill their task. The students are able to see how to effectively and operatively fulfill the certain assignment with no more worries but more happiness in comprehending the instruction and the passage as well. 
Metacognitive strategy is one of the applicable theories that serve much more effective solutions to be ready with various challenges in the twentieth digital era, especially for those who find it quiet difficult and hard to understand the online passage or regain the correct answers thoroughly. This strategy actually supplies a coercive effective and alternative way for the students to answer the questions aright. Thence, the usefulness of metacognitive strategy helps the students comprehends the passage in deeper way. Lastly, after applying the metacognitive strategy, the students are also capable of relating their prior knowledge, experience and memory to the reading material. It is suggested to implement this strategy in their forthcoming reading process not only for learning English online reading comprehension but also for the other subjects. Finally, it can be stated that metacognitive strategies cover all the students' problem with the effective solutions to ameliorate their learning skills.

The goal of the study proved that metacognitive strategy brought intensive and effective changes on the students' trick and comprehension toward the online reading material. As the result, the students could achieve better score and better self-confidence to solve challenges in their learning process to surely obtain better progress. The result of the present study is harmonious with the previous studies' conclusion. In general, the metacognitive is an effective and operative way assisting the students to comprehend the reading passage. (e.g., Anita, 2019; Usman \& Aziz, 2017; Jaleel, 2016; Misa, 2014).

\section{CONCLUSION}

The computation of Paired Sample T-test demonstrated that the Significance (2-tailed) value was 0.000 , it was significance at 0.05 level. This result clearly showed the difference between the students' average mean pretest score and the students' average mean posttest score after implementing the metacognitive strategy is significant. The researcher reasons out that the second-year students of MA Al-Istiqomah who taught online reading comprehension using metacognitive strategy accomplish better score and comprehension. This can be inferred that metacognitive strategy is an effective way to ameliorate the students' ability in online reading process.

Afterward, the researcher proposes some suggestions to the EFL teachers and learners as well as further researchers. For EFL teachers, metacognitive strategy is one of effective, applicable and operative glide path which can fully assist the students in online English reading comprehension material. The teacher can imply the metacognitive strategy into the lesson plans then formulating the appropriate materials. For the learners, metacognitive strategy is one of an effective and comprehensive way in obtaining the points of passages. The learners could apply it to get the better grade of English proficiency indeed. Lastly, for further researchers, this present study is one of decorous acknowledgement to the upcoming researchers who are interested in metacognitive strategy with more variables and more varieties to be practiced in English teaching learning process.

\section{REFERENCES}

Ahmad, S., Prahmana, R. C. I., Kenedi, A. K., Helsa, Y., Arianil, Y., \& Zainil, M. (2018). The instruments of higher order thinking skills. Journal of Physics: Conference Series, 943(1). https://doi.org/10.1088/1742-6596/943/1/012053

Antoni, N. (2010). An Analysis of Teacher's Strategies in Teaching Reading Comprehension. Jurnal Penelitian Pendidikan, 11(2).

Ciampa, K. (2012). The effects of an online reading program on grade 1 students' engagement and comprehension strategy use. Journal of Research on Technology in Education, 45(1), $27-59$. https://doi.org/10.1080/15391523.2012.10782596

Coiro, J. (2014). Research on the Effectiveness of Online Learning - A Compilation of Research on Online Learning. Texto Livre: Linguagem e Tecnologia, 7, 30-43. https://doi.org/http://dx.doi.org/10.17851/1983-3652.7.2.30-43

Doulík, P., Iř́, Š., \& Ríčan, J. (2015). Metacognitive strategies: asset to efficient learning and education. Dies Journal, 2015, Vol. 4, No. 1, p. 62-81. ISSN 1339-8660., 4, 62-81. 
Eleni Mitsea, A. D. (2019). A Journey into the Metacognitive Learning Strategies. IJOE, 14, 18.

Etfita, F. (2014). Improving Students' Reading Comprehension of Descriptive Texts Through

Cognitive Strategy at Grade VII-2 of SMPN 1 Indra Praja Tembilahan. Lingua Didaktika, 7(2), 75-86.

Ganie, R., . D., \& Rangkuti, R. (2019). Reading Comprehension Problems on English Texts Faced By High School Students in Medan. KnE Social Sciences, 2019, 684-694. https://doi.org/10.18502/kss.v3i19.4896

Hapsari, A. D. (2019). Metacognitive Strategy Training in The Teaching of Reading Comprehension: Is It Effective in EFL Classroom? LangEdu Journal, 14.

Jaleel, S., \& Premachandran. (2016). A Study on the Metacognitive Awareness of Secondary School Students. Universal Journal of Educational Research, 4, 165-172. https://doi.org/DOI: 10.13189/ujer.2016.040121

Latief, A. M. (2016). Research Methods on Language Learning: an Introduction. Malang. Universitas Negeri Malang.

Liu, Z. L., \& Jansen, B. (2015). Subjective versus Objective Questions: Perception of Question Subjectivity in Social Q\&A. Springer International Publishing Switzerland, 131-140. https://doi.org/DOI: 10.1007/978-3-319-16268-3_14

Misa, M. (2014). The Use of Guided Metacognitive Strategy to Improve Students' Reading Comprehension. Jurnal Pendidikan Humaniora, 4, 304-310.

Setiyadi, R., Kuswendi, U., \& Ristiyana, G. M. (2019). Learning of Reading Comprehension through Reading Workshop in the Industry 4.0. Mimbar Sekolah Dasar, 6, 160-173. https://doi.org/10.17509/mimbar- sd.v6i2.17397.

Usman, B., Aziz, Z., \& Riska, N. (2017). Improving Readng Comprehension Using Metacognitive Strategies. English Education Journal (EEJ), 8, 425-438. 